\title{
Empirical Sampling from Permutation Space with Unique Patterns
}

Justice I. Odiase

University of Benin, Nigeria

Follow this and additional works at: http://digitalcommons.wayne.edu/jmasm

Part of the Applied Statistics Commons, Social and Behavioral Sciences Commons, and the Statistical Theory Commons

\section{Recommended Citation}

Odiase, Justice I. (2012) "Empirical Sampling from Permutation Space with Unique Patterns," Journal of Modern Applied Statistical Methods: Vol. $11:$ Iss. 1 , Article 10.

DOI: $10.22237 /$ jmasm/1335845340

Available at: http://digitalcommons.wayne.edu/jmasm/vol11/iss1/10

This Regular Article is brought to you for free and open access by the Open Access Journals at DigitalCommons@WayneState. It has been accepted for inclusion in Journal of Modern Applied Statistical Methods by an authorized editor of DigitalCommons@WayneState. 


\title{
Empirical Sampling from Permutation Space with Unique Patterns
}

\author{
Justice I. Odiase \\ University of Benin, \\ Benin, Nigeria
}

The exact distribution of a test statistic ultimately guarantees that the probability of a Type I error is exactly $\alpha$. Several methods for estimating the exact distribution of a test statistic have evolved over the years with inherent computational problems and varying degrees of accuracy. The unique pattern of permutations resulting from using experimental data to sample within the permutation space without the risk of repeating permutations is identified. The method presented circumvents the theoretical requirements of asymptotic procedures and the computational difficulties associated with an exhaustive enumeration of permutations. Results show that time and space complexities are drastically reduced without compromising accuracy even when enumeration is not exhaustive provided error tolerance is achieved. The exact distribution of the Siegel-Tukey test statistic is examined as an illustration.

Key words: Algorithm, exact test, permutation test, bootstrap, resampling.

Introduction

The first edition of Fisher (1935) contains descriptions of two tests of significance that depend on permutation: Fisher's exact test for analyzing categorical data, and the permutation test for the difference between means. Many studies have been designed to confirm the asymptotic equivalence of permutation and classical tests (Ludbrook, 1994). Fisher wrote that "the statistician does not carry out this very simple and very tedious process, but his conclusions have no justification beyond the fact that they agree with those which could have been arrived at by this elementary method" (1936, p 59). Ernst (2004) noted that with fast computers there is little reason for a statistician not to carry out this very tedious process.

The main problem with permutation tests is that their null distributions are generally very difficult to express in closed form and to calculate exactly. This is because they depend

Justice Odiase is a Senior Lecturer in the Department of Mathematics, University of Benin, Benin City, Nigeria. Email him at: justice.odiase@uniben.edu. on a specific data set; thus they vary as the data varies in the sample space, however, for several test statistics involving ranks, the null distributions only need to be computed once. For large sample sizes, direct calculations are practically impossible due to the very large cardinality of associated permutation sample spaces. For example, a data set consisting of four treatments with five observations per treatment, $n_{i}=5, i=1(1) 4$, demands as many as

$$
\frac{\left(\sum_{\mathrm{i}=1}^{4} \mathrm{n}_{\mathrm{i}}\right) !}{\prod_{i=1}^{4}\left(\mathrm{n}_{\mathrm{i}} !\right)}=\frac{20 !}{5 ! 5 ! 5 ! 5 !}=11,732,745,024
$$

configurations for an exhaustive enumeration of all permutations. Pesarin (2001) stated that, unless sample sizes are very large, the approximation of such distributions by means of asymptotic arguments is not always appropriate. No general agreement exists regarding how large a sample should be before applying asymptotic approximation (Fahoome, 2000). Pesarin (2001) observed that the algorithms for exact calculations are generally based on direct calculus of upper tail probabilities; a strategy which may become highly impractical, if not 


\section{EMPIRICAL SAMPLING FROM PERMUTATION SPACE WITH UNIQUE PATTERNS}

impossible, in multivariate problems because there is no general computing routine useful to identify the critical regions. This was also observed by Hall and Weierserman (1997). In the early years of research into exact statistical inference, Scheffé (1943) clearly identified the fact that the permutation approach is the only way of constructing the exact distribution of a test statistic.

To avoid the computational difficulty in exact permutation tests, the conditional Monte Carlo (CMC) method was adopted by Pesarin (2001). In CMC replicate resampling is conducted without-replacement on the given data set, which is considered as playing the role of a finite population, provided that sample sizes are finite. According to Opdyke (2003), all existing permutation procedures developed to date can perform conventional Monte Carlo sampling without replacement within a sample but none can avoid the possibility of drawing the same sample more than once. The consideration given by Odiase and Ogbonmwan (2007) is an exception but involves a complete enumeration of all the distinct permutations, which becomes impracticable when the sample size is large.

In this study, the unique pattern of each permutation resulting from experimental data is identified and exploited in sampling from the permutation space without the attendant risk of repeating permutations. The method presented circumvents the elaborate theoretical requirements of asymptotic procedures and the logical and computational difficulties associated with an exhaustive enumeration of permutations.

\section{Exhaustive Permutation Procedures}

The process of obtaining permutations begins by choosing the test statistic $T$ and the acceptable significance level $\alpha$. Let $\pi_{1}, \pi_{2}$, $\ldots, \pi_{\mathrm{N}}$ be a set of all distinct permutations of the observations or ranks of the observations in the experiment. Compute the test statistic $T_{i}$ for permutation $\pi_{i}$, that is, $T_{i}=T\left(\pi_{i}\right)$. Construct an empirical cumulative distribution for $T$ as:

$$
p_{0}=\mathrm{p}\left(T \leq T_{\mathrm{i}}\right)=\frac{1}{\mathrm{~N}} \sum_{\mathrm{i}=1}^{\mathrm{N}} \psi\left(\mathrm{t}_{0}-T_{\mathrm{i}}\right),
$$

$$
\psi(\cdot)= \begin{cases}1, & \text { if } \mathrm{t}_{0} \geq T_{\mathrm{i}} \\ 0, & \text { if } \mathrm{t}_{0}<T_{\mathrm{i}}\end{cases}
$$

Under the empirical distribution, if $p_{0} \leq \alpha$, reject the null hypothesis.

\section{Paired Permutation}

Given two paired samples $X=\left(x_{1}, x_{2}, \ldots\right.$, $\left.x_{n}\right)$ and $Y=\left(y_{1}, y_{2}, \ldots, y_{n}\right)$, suppose a sample of $n$ units from the population distribution $F_{X}$ is paired with a sample of $n$ units from the population distribution $F_{Y}$ and are simultaneously tested in an experiment with $T$ as the test statistic. For $k$ distinct values of the test statistic $T$, the probability distribution of the test statistic $T=\left(T_{1}, T_{2}, \ldots, T_{k}\right)$ under the null hypothesis $H_{0}: F_{X}=F_{Y}$ is given by

$$
\mathrm{P}\left(T_{j}=t_{0} \mid H_{0}\right)={ }_{\sum_{i=1}^{f}}^{f}\left(2^{-n}\right)=f_{j}\left(2^{-n}\right),
$$

where $f_{j}$ is the number of occurrences of $T_{j}$. For specified value of $n$ and the level of significance $\alpha$, the critical value $c$ corresponds to a level closest to $\alpha$. Ordering all the distinct occurrences of $T$ in ascending order of magnitude, and if $g$ is the position of the observed value of $T$, then the following significance level for the left tail of the distribution of the test statistic is

$$
\alpha=\mathrm{P}\left(T_{g} \leq c \mid H_{0}\right)=\sum_{j=1}^{g} \sum_{i=1}^{f}\left(2^{-n}\right)=\left(2^{-n}\right) \sum_{j=1}^{g} f_{j}
$$

and, for the right tail,

$$
\alpha=\mathrm{P}\left(T_{g} \geq c \mid H_{0}\right)=\left(2^{-n}\right) \sum_{j=g}^{k} f_{j} .
$$

For a two-tailed test, the left and right tails are summed. If the distribution of the test statistic is symmetric, then

$$
\sum_{j=1}^{g} f_{j}=\sum_{j=k-g+1}^{k} f_{j}
$$

where 


\section{JUSTICE I. ODIASE}

The distribution of the test statistic is obtained by tabulating the distinct values of the statistic against their probabilities of occurrence in the complete enumeration (see Odiase \& Ogbonmwan, 2007a for a detailed description of the implementation of the paired permutation algorithm). Given a balanced two-sample layout as

$$
\left(\begin{array}{cc}
x_{1} & y_{1} \\
x_{2} & y_{2} \\
\vdots & \vdots \\
x_{n} & y_{n}
\end{array}\right)
$$

where $x_{i} \in X$ and $y_{j} \in Y$. If $n=4$, then, for a two-sample problem, the number of permutations is $\sum_{i=0}^{n}\left(\begin{array}{l}n \\ i\end{array}\right)=2^{n}$.

The test statistic is computed for each permutation in the complete enumeration of the distinct permutations. The distribution of the test statistic is obtained by tabulating the distinct values of the statistic against their probabilities of occurrence in the complete enumeration, where all the permutations are equally likely.

Considering consecutive number of pairs for a given experiment, the growth rate of the permutations from $n-1$ pairs to $n$ pairs in a two-sample paired permutation experiment is $\frac{2^{n}}{2^{n-1}}=2$, meaning that it doubles each time a single pair of observations is added.

Independent Samples Experiment Given a multi-sample experiment with $X_{i}=\left(X_{i 1}, X_{i 2}, \ldots, X_{i n_{i}}\right)^{T}, i=1(1) p$ and $\boldsymbol{X}_{N}=$ $\left(X_{1}, X_{2}, \ldots, X_{p}\right)$. Under the null hypothesis, $X_{N}$ is composed of $N=\sum_{i=1}^{p} n_{i}$ independent and identically distributed random variables. An exhaustive permutation of the observations yields $\frac{\boldsymbol{N} !}{\boldsymbol{P}}$ permutations of the $N$ variates $\prod_{i=1}\left[\left(n_{i}\right) !\right]$

of $p$ subsets of size $n_{i}, i=1(1) p$, which are equally likely and each has the conditional probability $\left(\frac{N !}{\prod_{i=1}^{P}\left[\left(n_{i}\right) !\right]}\right)^{-1} \cdot \quad$ Odiase and

Ogbonmwan (2005a) showed that the number of permutations for a two-sample experiment is $\sum_{i=0}^{n}\left(\begin{array}{c}n_{1} \\ i\end{array}\right)\left(\begin{array}{c}n_{2} \\ i\end{array}\right), \mathrm{n}=\min \left(\mathrm{n}_{1}, \mathrm{n}_{2}\right)$. After obtaining the permutations of a two sample experiment, find the number of ways to permute any $n_{3}$ elements of the combined $\left(\mathrm{n}_{1}+\mathrm{n}_{2}+\mathrm{n}_{3}\right)$ variates of the three treatments. This yields:

$\left(\begin{array}{c}n_{1}+n_{2}+n_{3} \\ n_{3}\end{array}\right) \sum_{i=0}^{n}\left(\begin{array}{c}n_{1} \\ i\end{array}\right)\left(\begin{array}{c}n_{2} \\ i\end{array}\right)=\left(\begin{array}{c}\sum_{r=1}^{3} n_{r} \\ n_{3}\end{array}\right) \sum_{i=0}^{n}\left(\begin{array}{c}n_{1} \\ i\end{array}\right)\left(\begin{array}{c}n_{2} \\ i\end{array}\right)$.

By following the same procedure as for the case of three treatments, a complete enumeration of the distinct permutations for a four-treatment experiment yields:

$$
\begin{array}{r}
\left(\begin{array}{c}
\sum_{r=1}^{4} n_{r} \\
n_{4}
\end{array}\right)\left(\begin{array}{c}
\sum_{r=1}^{3} n_{r} \\
n_{3}
\end{array}\right) \sum_{i=0}^{n}\left(\begin{array}{c}
n_{1} \\
i
\end{array}\right)\left(\begin{array}{c}
n_{2} \\
i
\end{array}\right)= \\
\prod_{j=3}^{4}\left(\begin{array}{c}
\sum_{r=1}^{j} n_{r} \\
n_{j}
\end{array}\right) \sum_{i=0}^{n}\left(\begin{array}{c}
n_{1} \\
i
\end{array}\right)\left(\begin{array}{c}
n_{2} \\
i
\end{array}\right) .
\end{array}
$$

Continuing in this manner, for $\mathrm{p} \geq 3$ treatments, the distinct permutations are enumerated through the expression

$$
\prod_{j=3}^{p}\left(\begin{array}{c}
\sum_{r=1}^{j} n_{r} \\
n_{j}
\end{array}\right) \sum_{i=0}^{n}\left(\begin{array}{c}
n_{1} \\
i
\end{array}\right)\left(\begin{array}{c}
n_{2} \\
i
\end{array}\right)
$$

but

$$
\sum_{i=0}^{n}\left(\begin{array}{c}
n_{1} \\
i
\end{array}\right)\left(\begin{array}{c}
n_{2} \\
i
\end{array}\right)=\left(\begin{array}{c}
\sum_{r=1}^{2} n_{r} \\
n_{2}
\end{array}\right)
$$


Therefore, in a p-sample problem, the number of distinct permutations is $\prod_{j=1}^{p}\left(\begin{array}{c}\sum_{r=1}^{j} n_{r} \\ n_{j}\end{array}\right)$ (Odiase \& Ogbonmwan, 2005b). Observe that, for the balanced case, the number of distinct permutations is

$$
\prod_{\mathrm{j}=3}^{\mathrm{p}}\left(\begin{array}{c}
j n \\
n
\end{array}\right) \sum_{\mathrm{i}=0}^{\mathrm{n}}\left(\begin{array}{c}
\mathrm{n} \\
\mathrm{i}
\end{array}\right)^{2}=\prod_{\mathrm{j}=1}^{\mathrm{p}}\left(\begin{array}{c}
j n \\
n
\end{array}\right) .
$$

Again, considering consecutive number of treatments for a given experiment, the growth rate of the permutations from $p-1$ treatments to $p$ treatments is

$$
\prod_{\mathrm{j}=1}^{\mathrm{p}}\left(\begin{array}{c}
j n \\
n
\end{array}\right) / \prod_{\mathrm{j}=1}^{\mathrm{p}-1}\left(\begin{array}{c}
j n \\
n
\end{array}\right)=\left(\begin{array}{c}
\mathrm{np} \\
\mathrm{n}
\end{array}\right) \text {. }
$$

Repeated Measures (Block) Permutation

Repeated measures ANOVA tests the equality of means and is used when all members of a random sample are measured under varying conditions. In the repeated measures design, each trial represents the measurement of the same characteristic under a different condition. Given the layout of a multi-sample $\left(\begin{array}{lll}n & \mathrm{x} & k\end{array}\right)$ experiment as

$$
\left(\begin{array}{cccc}
x_{11} & x_{12} & \cdots & x_{1 k} \\
x_{21} & x_{22} & \cdots & x_{2 k} \\
\vdots & \vdots & \vdots & \vdots \\
x_{n 1} & x_{n 2} & \cdots & x_{n k}
\end{array}\right)
$$

where $\mathrm{x}_{\mathrm{ij}}$ is an observation in the $j^{\text {th }}$ treatment and the $i^{\text {th }}$ block and the total number of observations in the experiment is $n k$. Rank the observations for each row from 1 (smallest $x_{i j}$ on row $i$ ) to $k$ (largest $x_{i j}$ on row $i$ ). Let the layout of the ranks $\left(r_{i j}\right)$ of the observations $x_{i j}$ be

$$
L_{R}=\left(\begin{array}{cccc}
r_{11} & r_{12} & \cdots & r_{1 k} \\
r_{21} & r_{22} & \cdots & r_{2 k} \\
\vdots & \vdots & \vdots & \vdots \\
r_{n 1} & r_{n 2} & \cdots & r_{n k}
\end{array}\right)
$$

The data are arranged in $k$ columns (treatments) and $n$ rows (blocks), where each block contains $k$ repeated observations. Obviously, there are $k$ ! possible arrangements or permutations of each block and due to multiplication of choices, the entire layout of the $n \times k$ experiment requires $(k !)^{n}$ permutations of the observations to yield the exact distribution of a test statistic, with the permutations equally likely and each having the conditional probability $(k !)^{-n}$.

The first step in developing permutation algorithm is to formulate an initial configuration of the ranks of the variates of an experiment by taking the trivial configuration

$$
\begin{array}{cccccc} 
& \operatorname{Tr} .1 & \operatorname{Tr} .2 & \operatorname{Tr} .3 & \cdots & \operatorname{Tr} . k \\
\text { Block } 1 & 1 & 2 & 3 & \cdots & k \\
\text { Block2 } & 1 & 2 & 3 & \cdots & k \\
\text { Block } 3 & 1 & 2 & 3 & \cdots & k \\
\vdots & \vdots & \vdots & \vdots & \cdots & \vdots \\
\text { Blockn } & 1 & 2 & 3 & \cdots & k
\end{array}
$$

because any configuration of the ranks can engender all the distinct permutations. The test statistic is computed for each permutation in the complete enumeration of all the distinct permutations. The distribution of the test statistic is obtained by tabulating the distinct values of the test statistic against their probabilities of occurrence in the complete enumeration.

Considering two consecutive numbers of blocks for a given experiment, the growth rate of the permutations from $n-1$ blocks to $n$ blocks is $\frac{(k !)^{n}}{(k !)^{n-1}}=k !$ and the growth rate of the permutations from $k-1$ treatments to $k$ treatments is $\frac{(k !)^{n}}{[(k-1) !]^{n}}=k^{n}$ and clearly, $k$ ! grows faster than $k^{n}$ for a fixed $n$, and for a fixed 


\section{JUSTICE I. ODIASE}

$k, k$ ! is constant while $k^{n}$ explodes as $n$ increases. Therefore, the growth rate of the permutations is higher for a unit increase in blocks than a unit increase in treatments for a fixed number of treatments and the reverse is the case when it is the number of blocks that is fixed.

Sampling Permutations with Unique Patterns Given the layout of a two-sample experiment as

$$
\left(\begin{array}{cc}
x_{1} & y_{1} \\
x_{2} & y_{2} \\
\vdots & \vdots \\
x_{1 n_{1}} & y_{n_{2}}
\end{array}\right)
$$

where $x_{i}$ and $y_{i}$ are the $i^{\text {th }}$ observations of the independent random samples $\mathrm{X}$ and $\mathrm{Y}$ respectively, arrange the combined samples in ascending order of magnitude and rank all the $m=n_{1}+n_{2}$ observations from 1 (smallest) to $m$ (largest). Let the layout of the ranks $\left(r_{i j}\right)$ of the observations in a two-sample layout be

$$
L_{R}=\left(\begin{array}{cc}
r_{11} & r_{21} \\
r_{12} & r_{22} \\
\vdots & \vdots \\
r_{1 n_{1}} & r_{2 n_{2}}
\end{array}\right) \text {. }
$$

Under the null hypothesis, $L_{R}$ is composed of $m$ independent and identically distributed random variables and hence conditioned on the observed data set. An exhaustive permutation of the ranks yields $N=\frac{m !}{n_{1} ! n_{2} !}$ permutations of the $m$ ranks of the variates of two subsets of sizes $n_{1}$ and $n_{2}$, which are equally likely, each having the conditional probability $N^{-1}$.

The unique pattern of each permutation resulting from experimental data is identified by adopting the first sample, for example, in a twosample problem. This is carried out by concatenating the ranks or indices of observations in the experiment in a particular manner that makes the pattern unique for every distinct permutation. The unique patterns obtained are therefore exploited in sampling from the permutation space without the risk of repeating permutations already sampled. The benefit of this approach is that - even when enumeration is not exhaustive - the distribution of a test statistic can be obtained within a reasonable level of accuracy with reduced time and space complexities. This sampling approach therefore circumvents the elaborate theoretical requirements of asymptotic procedures and the logical and computational difficulties associated with an exhaustive enumeration of permutations.

\section{Methodology}

Let the initial configuration of the ranks of the variate in a two-sample experiment be $L_{R}$. The entire permutation space can be spanned by any of the permutations (configurations) of the observations or ranks of observations. In a twosample problem, only one of the samples is required to define each permutation because it is obvious that the remaining variates are in the second sample.

In a two-sample experiment

$$
\left(\begin{array}{cc}
x_{1} & y_{1} \\
x_{2} & y_{2} \\
\vdots & \vdots \\
x_{1 n_{1}} & y_{n_{2}}
\end{array}\right),
$$

where $x_{i}$ and $y_{i}$ are the $i^{\text {th }}$ observations of the independent random samples $\mathrm{X}$ and $\mathrm{Y}$ respectively, arrange the combined samples in ascending order of magnitude and rank all the $m=n_{1}+n_{2}$ observations from 1 (smallest) to $m$ (largest) to arrive at $L_{R}$. For the original permutation and subsequent permutations, sort $\mathrm{X}$ such that $x_{1} \leq x_{2} \leq \cdots \leq x_{n_{1}}$.

The variates are identified by their indices $(1,2, \ldots, m)$ or actual ranks, which are employed in obtaining the unique patterns. Attach 0 in front of the first nine indices or ranks $(01,02, \ldots, 09)$ to make each number two digits, leaving $10,11, \ldots, 99$ as they are and treat all the numbers as strings so that it will be possible to manipulate the numbers. Concatenate the indices or ranks of $\mathrm{X}$ and store as a single constant value. This now becomes the pattern of the 


\section{EMPIRICAL SAMPLING FROM PERMUTATION SPACE WITH UNIQUE PATTERNS}

given layout of the observations. (Concatenation is a standard operation in computer programming languages. It is the operation of joining two character strings end to end. In programming languages, string concatenation is a binary operation usually accomplished by putting a concatenation operator between two strings or operands.)

After a unique pattern is obtained, a resampling without replacement is carried out to obtain a random sample of $n_{l}$ variates from the original combined sample of $m$ variates. This is achieved by deleting points already selected at random. Again, sort the resampled $n_{l}$ variates and concatenate their indices or ranks to obtain a pattern. Compare this pattern with previously obtained patterns and store it only if it is unique, otherwise, resample without replacement again until a unique pattern is obtained. The chosen test statistic is computed for each unique permutation and the probability distribution of the test statistic is constructed. Finally, compute the cumulative probability distribution of the test statistic, $T$, under the null hypothesis and obtain the $p$-values such that the probability of making a Type I error is exactly $\alpha$.

As an illustration, consider an $n \times k$ experiment with $n=2$ treatments $(\mathrm{X}, \mathrm{Y})$ and $k=$ 5 variates in each treatment could have the trivial configuration or permutation of ranks represented as

$\begin{array}{cc}X & Y \\ 1 & 6 \\ 2 & 7 \\ 3 & 8 \\ 4 & 9 \\ 5 & 10\end{array}$

Using the methodology presented, the permutation is written as

$\begin{array}{ll}X & Y \\ 01 & 06 \\ 02 & 07 \\ 03 & 08 \\ 04 & 09 \\ 05 & 10\end{array}$

a total of $\frac{10 !}{5 ! \times 5 !}=252$ permutations are required for an exhaustive enumeration of all the distinct or unique permutations. The process starts thus: The entire permutation space can be spanned by the trivial permutation (configurations) of the observations or ranks of observations, any other permutation from the permutation space can also be adopted to span all the unique permutations. In a two-sample problem, only one of the samples $(\mathrm{X})$ is required to define each permutation because it is clear that the remaining variates are in the second sample.

The first permutation pattern is 0102030405. Assuming resampling from the permutation space yields $X=\{8,3,5,2,6\}$, then the second permutation pattern is obtained by first sorting to have $\{2,3,5,6,8\}$, leading to the pattern 0203050608. Resampling again, given $\{2,10,5,9,8\}$, the third permutation pattern is 0205080910. The resampling process continues until either all the patterns are enumerated for small samples or the error tolerance is achieved for large samples. See Table 1 for an exhaustive enumeration of the $\frac{10 !}{5 ! \times 5 !}=252$ permutation patterns for this illustration.

For very small samples, an exhaustive enumeration of all the unique permutations is achieved with the sampling method described. When sample size is large, enumeration of permutations does not need to be exhaustive. Instead, a subset of the permutation space (for example, 2,000) is obtained and the probability distribution of the test statistic is constructed. Take a second sample of same size and fuse it into the earlier distribution to obtain an updated probability distribution and compare with the earlier distribution. With a given level of error 


\section{JUSTICE I. ODIASE}

Table 1: Exhaustive Enumeration of Unique Permutation Patterns for $n=2, k=5$

\begin{tabular}{|c|c|c|c|c|c|}
\hline 0102030405 & 0304050710 & 0103050709 & 0405070809 & 0304070810 & 0105060708 \\
\hline 0203050608 & 0206070809 & 0105060910 & 0102030408 & 0203060708 & 0405060708 \\
\hline 0106070809 & 0102030910 & 0102040910 & 0205080910 & 0102060810 & 0102030506 \\
\hline 0104050809 & 0102050609 & 0102060709 & 0204050708 & 0304060708 & 0506080910 \\
\hline 0104080910 & 0102030709 & 0304050709 & 0102040608 & 0206070810 & 0305060710 \\
\hline 0104060708 & 0205060809 & 0104060809 & 0102030510 & 0204050610 & 0102070809 \\
\hline 0203040708 & 0104060710 & 0306070809 & 0307080910 & 0102040609 & 0102040710 \\
\hline 0507080910 & 0103040508 & 0103040810 & 0305080910 & 0103040507 & 0102040709 \\
\hline 0203060810 & 0306070810 & 0203040510 & 0205070810 & 0105080910 & 0106080910 \\
\hline 0102060710 & 0103050610 & 0204070910 & 0103050810 & 0203060809 & 0204050809 \\
\hline 0102030409 & 0102030407 & 0204060708 & 0506070809 & 0102050910 & 0205070910 \\
\hline 0304050910 & 0405060910 & 0102060809 & 0103060910 & 0104060709 & 0103040506 \\
\hline 0203040508 & 0205060910 & 0205060810 & 0103060709 & 0204060910 & 0203040610 \\
\hline 0304050708 & 0104070809 & 0103050710 & 0105060710 & 0102030509 & 0304050609 \\
\hline 0102030607 & 0406080910 & 0304050809 & 0103040708 & 0203050910 & 0204080910 \\
\hline 0203040810 & 0104070910 & 0102040509 & 0104050910 & 0203050609 & 0304070809 \\
\hline 0103060710 & 0103040608 & 0406070809 & 0103050609 & 0107080910 & 0104070810 \\
\hline 0106070810 & 0204050910 & 0305060708 & 0203040609 & 0102030609 & 0106070910 \\
\hline 0405060710 & 0304060910 & 0304050610 & 0103040609 & 0102050809 & 0102040506 \\
\hline 0203040506 & 0102030406 & 0104050607 & 0204070810 & 0103070810 & 0203040509 \\
\hline 0102040610 & 0304060809 & 0102040810 & 0103050708 & 0405060709 & 0203060910 \\
\hline 0203040607 & 0104050709 & 0204050709 & 0102080910 & 0206080910 & 0102030810 \\
\hline 0205060710 & 0103040809 & 0103060708 & 0203060710 & 0405060809 & 0204060710 \\
\hline 0104050609 & 0102060910 & 0104050710 & 0102070910 & 0103060810 & 0304080910 \\
\hline 0103060809 & 0203050607 & 0102040507 & 0102030708 & 0203040709 & 0204050810 \\
\hline 0105060709 & 0207080910 & 0304070910 & 0204050710 & 0203070809 & 0103040710 \\
\hline 0102040508 & 0305060809 & 0103050809 & 0102030410 & 0103040607 & 0205060709 \\
\hline 0105070810 & 0103040510 & 0405070910 & 0405060810 & 0607080910 & 0204060809 \\
\hline 0102030710 & 0102070810 & 0203080910 & 0204060810 & 0406070910 & 0405070810 \\
\hline 0203050809 & 0203060709 & 0204060709 & 0103080910 & 0105070809 & 0204050607 \\
\hline 0102030507 & 0103070809 & 0102050607 & 0103050910 & 0104050810 & 0105070910 \\
\hline 0203040608 & 0204050609 & 0104060810 & 0203040809 & 0103070910 & 0102040607 \\
\hline 0103040610 & 0103050607 & 0206070910 & 0102040809 & 0506070910 & 0304060709 \\
\hline 0305060810 & 0306080910 & 0203040710 & 0105060809 & 0102060708 & 0203050709 \\
\hline 0102050710 & 0203070910 & 0304060710 & 0104060910 & 0304050608 & 0102030608 \\
\hline 0203050610 & 0102030508 & 0102030809 & 0406070810 & 0103050608 & 0204070809 \\
\hline 0102030610 & 0203040507 & 0405080910 & 0102040708 & 0105060810 & 0103040509 \\
\hline 0305060910 & 0205070809 & 0103040709 & 0304050607 & 0203040910 & 0203050708 \\
\hline 0306070910 & 0305070910 & 0102040510 & 0304060810 & 0305070809 & 0203070810 \\
\hline 0204050608 & 0205060708 & 0103040910 & 0304050810 & 0407080910 & 0102050608 \\
\hline 0305060709 & 0104050608 & 0104050610 & 0203050810 & 0506070810 & 0102050610 \\
\hline 0305070810 & 0104050708 & 0203050710 & 0102050708 & 0102050709 & 0102050810 \\
\hline
\end{tabular}


tolerance, if the error tolerance is exceeded, another sample is taken and fused into the last update of the probability distribution to obtain another update and again compared with the previous update of the probability distribution. This process is continued until the error tolerance is achieved. Compare for every occurrence of the test statistic in the last two updates using the error tolerance as a guide and proceed to update the probability distribution if the error tolerance is not met. Compute the cumulative probability distribution of the Test Statistic, $T$, under the null hypothesis and obtain the p-values such that the probability of making a type I error is exactly $\alpha$.

\section{Unique Permutation Pattern Test Procedure}

Let $\pi_{1}, \pi_{2}, \ldots, \pi_{\mathrm{N}}$ be a set of all distinct permutations of the ranks of the data set in the experiment. The unique permutation pattern test procedure is as follows:

1. Read the original layout of observations.

2. Rank the combined observations of the experiment in (1) to obtain $L_{R}=\pi_{1}$ and compute the observed value of $T$ statistic to obtain $T_{1}=t_{0}$.

3. Store pattern of (1) or (2).

4. Obtain a distinct permutation $\pi_{i}$, of the ranks $\left(L_{R}\right)$ from (3) by sampling without replacement.

5. Obtain pattern of (4) and compare with previous patterns. If different, store pattern, if already exists, go to (4).

6. Compute the $T$ statistic $T_{\mathrm{i}}=T\left(\pi_{i}\right)$, for permutation $\pi_{i}$ in (5), where $i>1$; update probability distribution.

7. Perform (4) to (6) for $i=2,3, \ldots, k \leq N$. If sample size $(\mathrm{N})$ is large,

a) Assume a level of error tolerance $(0.00001)$ and take a subset of size $\mathrm{k}=$ 1,000 of the permutation space to obtain the probability distribution of the test statistic.

b) Take another subset of size $\mathrm{k}$ from the permutation space and fuse into the earlier probability distribution to obtain an updated distribution. Compare this distribution with the earlier distribution of the test statistic for every value of the test statistic.

c) If the error tolerance is exceeded for any value of the test statistic, go back to (b); continue this process until the error tolerance is achieved.

8. Construct the empirical cumulative probability distribution for the distinct values of $T$ and extract critical values.

$$
p_{0}=p\left(T \leq T_{i}\right)=\frac{1}{k} \sum_{i=1}^{k} \psi\left(T_{i}-t_{0}\right)
$$

where

$$
\psi\left(T_{i}-t_{0}\right)=\left\{\begin{array}{ll}
1, & \text { if } T_{i} \leq t_{0} \\
0, & \text { if } \mathrm{T}_{i}>t_{0}
\end{array} .\right.
$$

9. Under the empirical distribution, if $p_{0} \leq \alpha$, reject the null hypothesis.

In a two-sample problem, only one of the samples is important in the generation of permutation patterns because it is unique for each permutation, that is,

$$
\left(\begin{array}{l}
m \\
n_{1}
\end{array}\right)=\left(\begin{array}{l}
m \\
n_{2}
\end{array}\right)=\frac{m !}{n_{1} ! n_{2} !}, m=n_{1}+n_{2} .
$$

To provide exact critical values when ties occur, midranks are assigned as the ranks of tied observations, and the algorithm is implemented with $r_{i j}$ as input, composed of actual ranks containing ties. Tabulated exact critical values of a test statistic are usually provided for experiments with distinct observations, because it will be practically difficult to consider all possible occurrences of ties and create tables of exact critical values for each occurrence of ties 


\section{JUSTICE I. ODIASE}

for different sample sizes. This will result in several volumes of tables. In order to arrive at the critical values (see Table 2), the ranks of distinct observations (rij) were used as input in Algorithm for various sample sizes. See Appendix A for the unique permutation pattern algorithm. This algorithm identifies and compiles the unique permutation patterns of the layout of observations or rank of observations in a two-sample experiment. It is illustratively implemented to produce a table of critical values for the Siegel-Tukey test statistic

\section{Siegel-Tukey Test}

The Siegel-Tukey test is similar in procedure to the Wilcoxon Rank Sum test for difference in location. It is based on the logic that if two samples come from populations with the same median, the one with the greater variability will have more extreme scores. The hypotheses for a two-tailed test are:

$H_{0}$ : There is no difference in spread between the two populations

versus

$H_{1}$ : There is some difference in spread between the two populations.

The two samples are combined and ordered in ascending order of magnitude, keeping track of sample membership. For $m=n_{1}+n_{2}$, the ranking proceeds as follows: $\alpha(1)=1, \alpha(m)=2, \alpha(m-1)=3, \alpha(2)=4$, $\alpha(3)=5, \quad \alpha(m-2)=6, \quad \alpha(m-3)=7$, $\alpha(4)=8$, the ranking continues to alternate from lowest to highest, ranking two scores at each end. It tests for differences in scale between two groups.

Critical Values for the Siegel-Tukey Test Statistic

Figures 1a-1b illustrate that the normal distribution will poorly approximate the exact distribution of the Siegel-Tukey (S-T) test statistic for very small sample sizes. As group sample size increases, the shape of the distribution of the S-T test begins to look more like the normal distribution as shown in Figures $1 \mathrm{c}-1 \mathrm{~d}$. The critical values of the S-T test statistic shown in Table 2 were obtained from the enumeration of all distinct permutations of the ranks of the observations in an experiment $(m, n$ $<20$ ) combined with the idea of resampling while ensuring an error tolerance level $(m, n \geq$ 20). These critical values ensure that the probability of a Type I error in decisions arising from the use of the S-T test is exactly $\alpha$.

Results obtained from asymptotic procedures and resampling techniques are commonly adopted in several nonparametric tests as alternatives to tabulated exact critical values. Fahoome (2002) conducted a Monte Carlo study and recommended the asymptotic approximation of the S-T test when group sample sizes exceed 25 , based on conservative estimates of $0.045<$ Type I error rate $<0.055$ for $\alpha=0.05$; other authors recommended higher or lower sample sizes.

\section{Conclusion}

The critical values for a test statistic are determined by cutting off the most extreme $100 \alpha \%$ of the theoretical frequency distribution of the test statistic, where $\alpha$ is the level of significance (Siegel \& Castellan, 1988). Classical methods require that the theoretical distribution of the test statistic should agree with a mathematically definable frequency distribution, this often leads to a probability of Type I error greater than $\alpha$, particularly when sample sizes are small. The cost of such an error might be too high to risk. Therefore, the exact permutation paradigm methodology presented in this study is of value because it guarantees that the probability of a Type I error is exactly $\alpha$ with the attendant advantage of no distributional assumptions apart from the exchangeability of the observations. When sample sizes are large and it becomes practically difficult or impossible to construct the probability distribution, permutation sampling becomes very useful because it quickly converges to the actual distribution; Scheffe (1943) opined that this is the only sure way of constructing the exact distribution of a test statistic. 
Figure 1: Exact Distribution of Siegel-Tukey Test Statistic (S-T) for Different Sample Sizes with their Large Sample Approximations (Z)

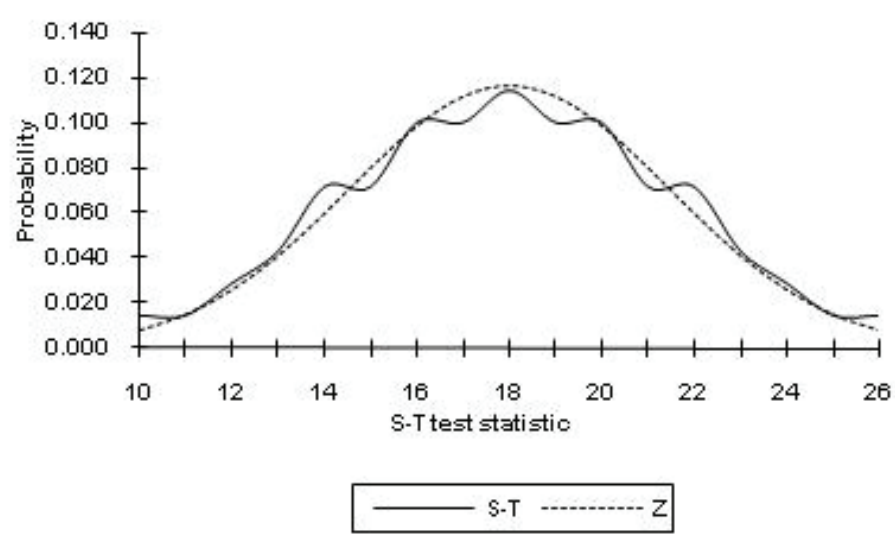

(a)

$$
n_{1}=4, n_{2}=4
$$

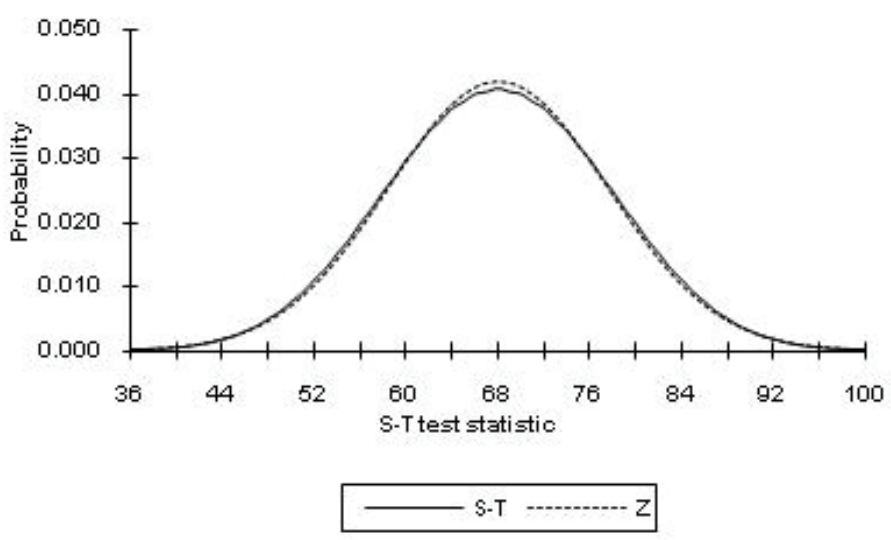

(c)

$n_{1}=8, n_{2}=8$

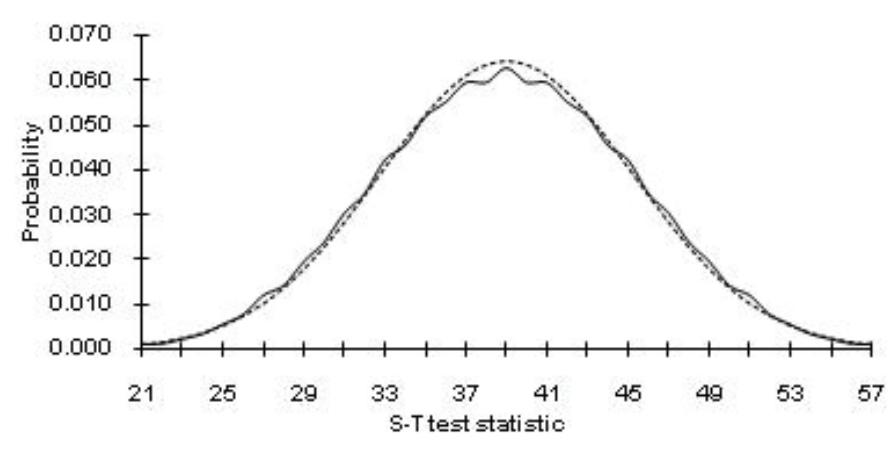

(b)

$n_{1}=6, n_{2}=6$

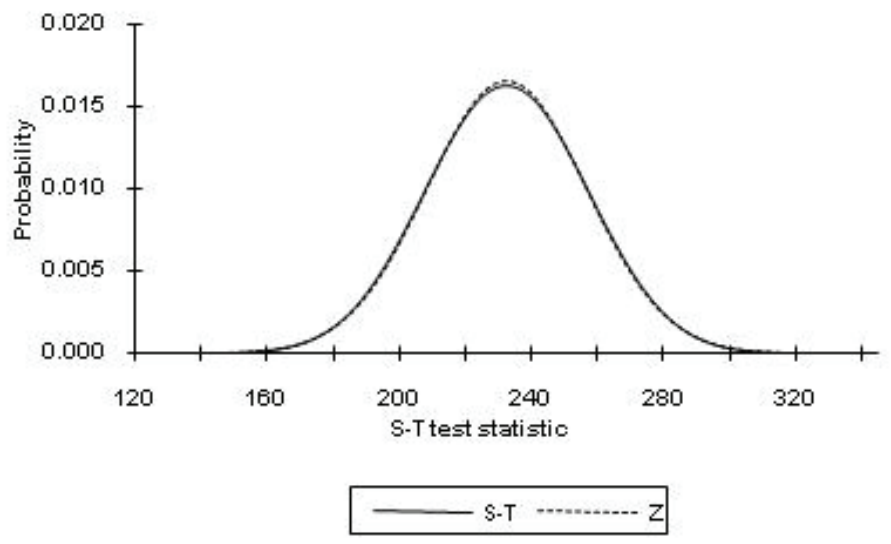

(d)

$n_{1}=15, n_{2}=15$ 


\section{JUSTICE I. ODIASE}

Figure 2: Distribution of Siegel-Tukey Test Statistic with Error Tolerance $=0.00001$ for Different Sample Sizes

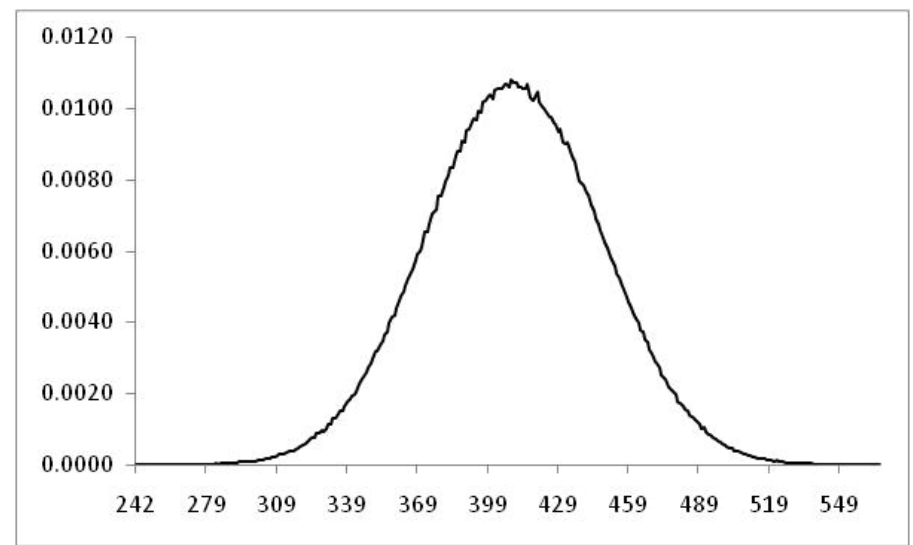

(a)

$n_{1}=20, n_{2}=20$

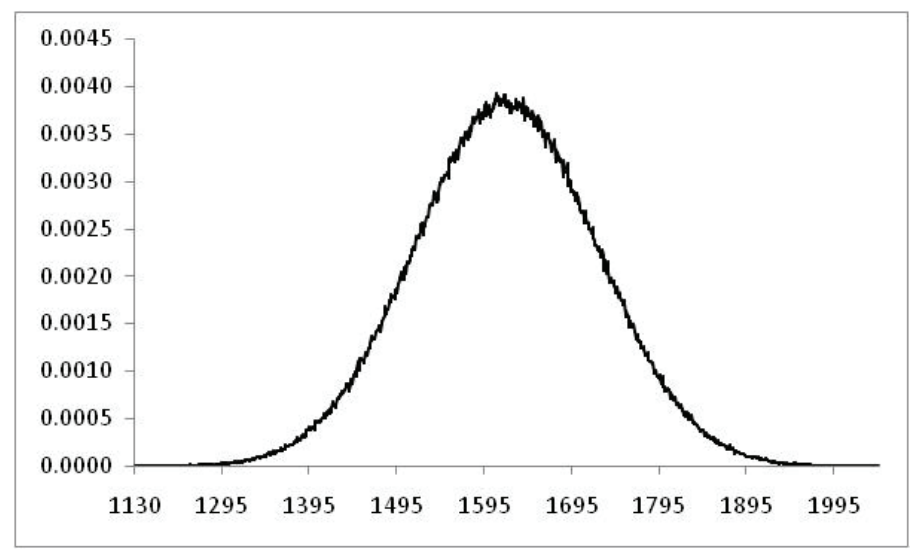

(c)

$n_{1}=40, n_{2}=40$

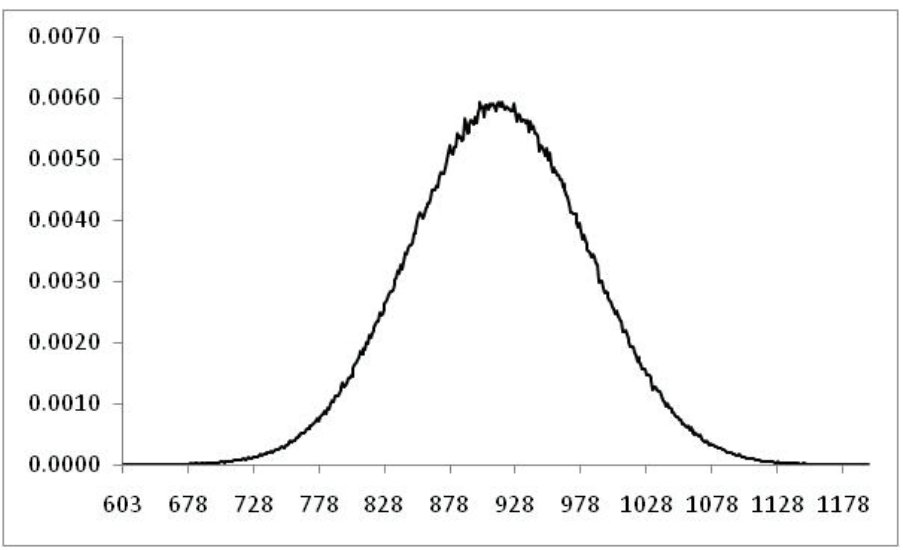

(b)

$$
n_{1}=30, n_{2}=30
$$

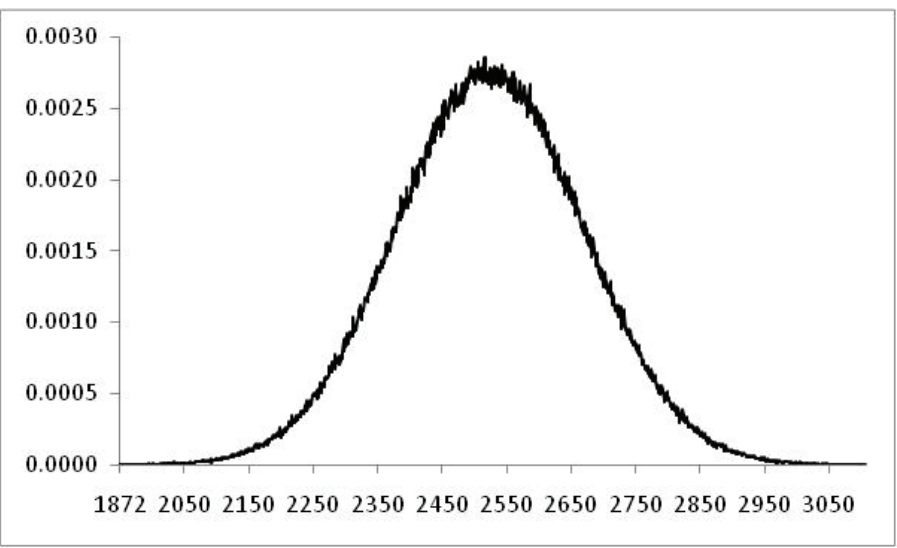

(d)

$n_{1}=50, n_{2}=50$ 
Figure 3: Distribution of Siegel-Tukey Test Statistic for Different Levels of Error Tolerance $\left(n_{l}=15, n_{2}=15\right)$

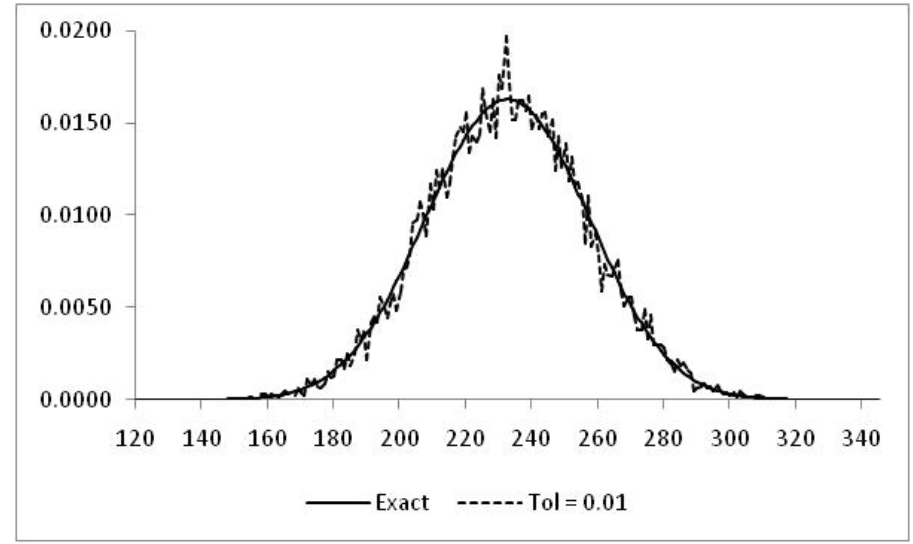

(a)

2 Iterations

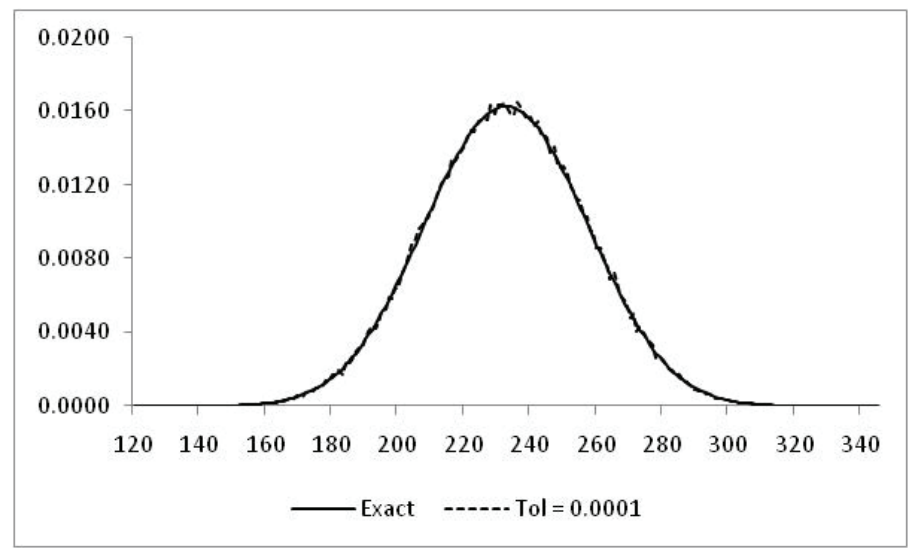

(c)

36 Iterations

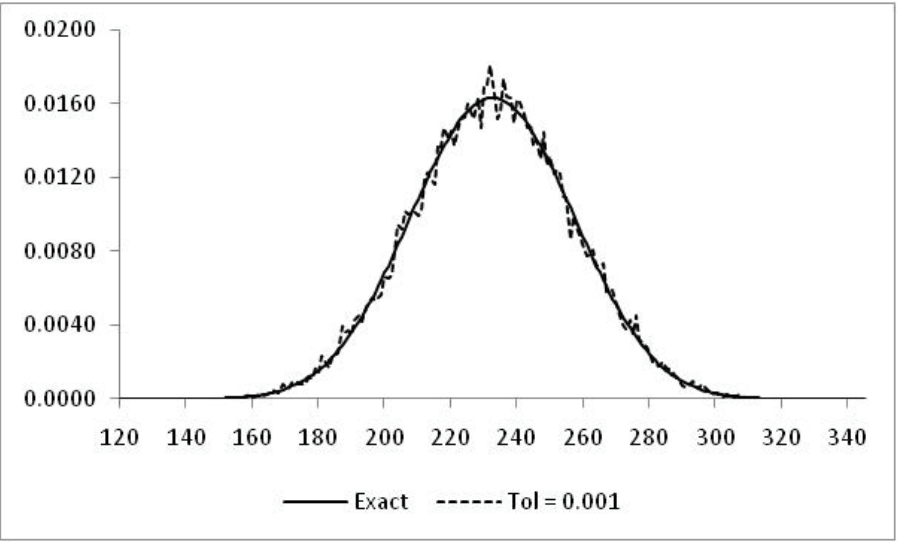

(b)

5 Iterations

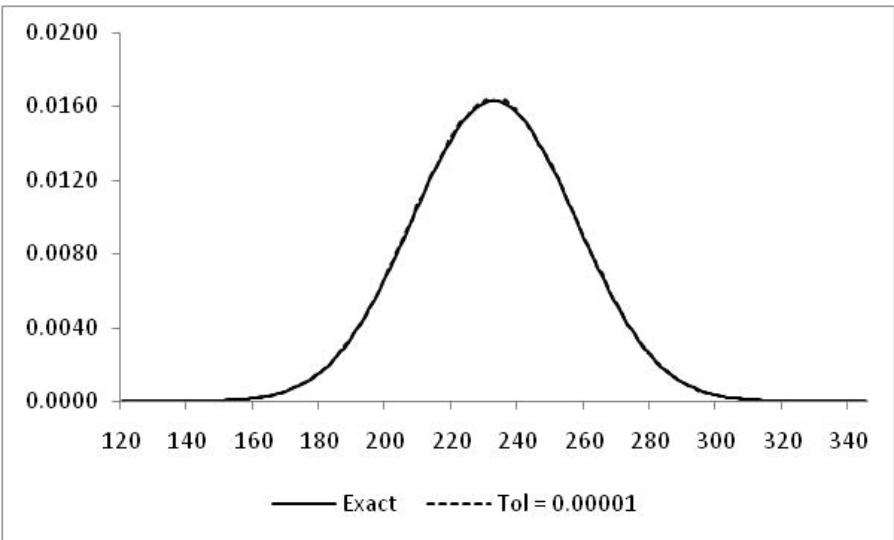

(d)

339 Iterations 


\section{JUSTICE I. ODIASE}

Figure 4: Distribution of Siegel-Tukey Test Statistic for Different Number Samples $\left(n_{1}=15, n_{2}=15\right)$

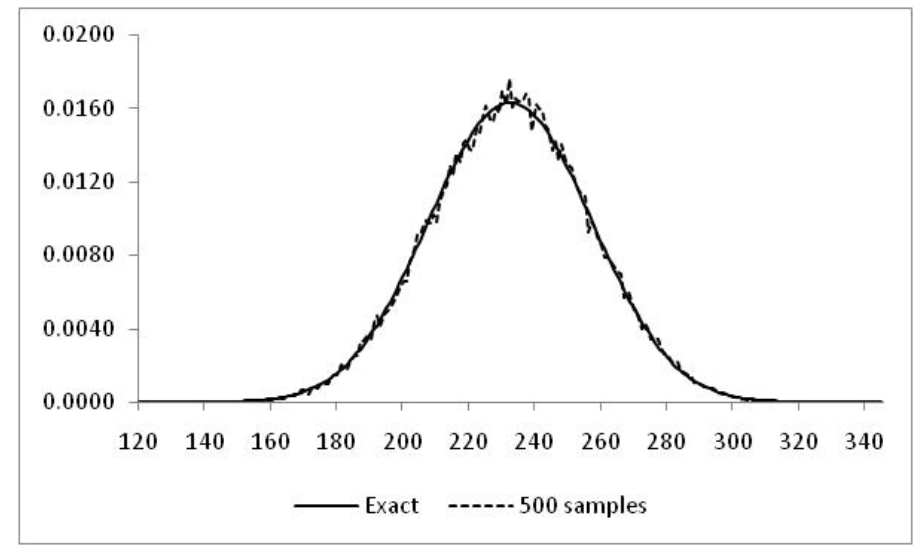

(a)

103 Iterations

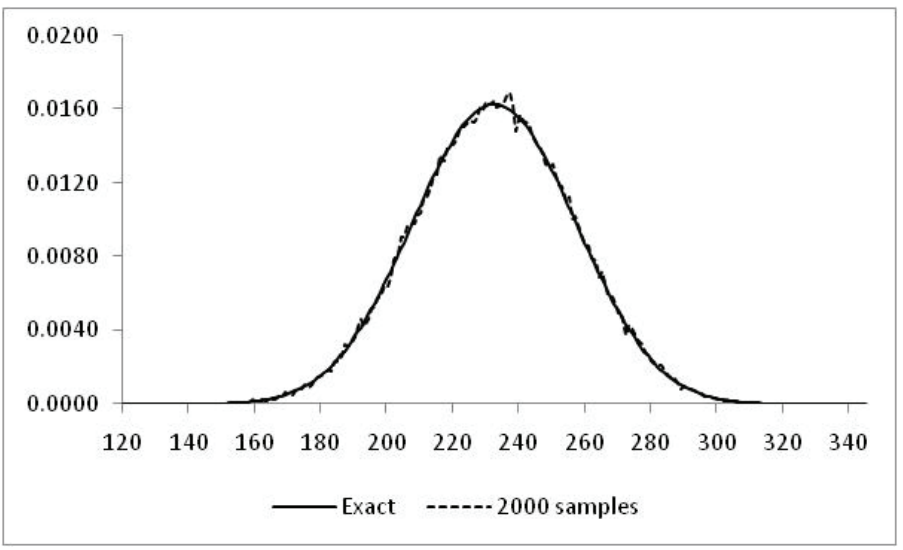

(c)

50 Iterations

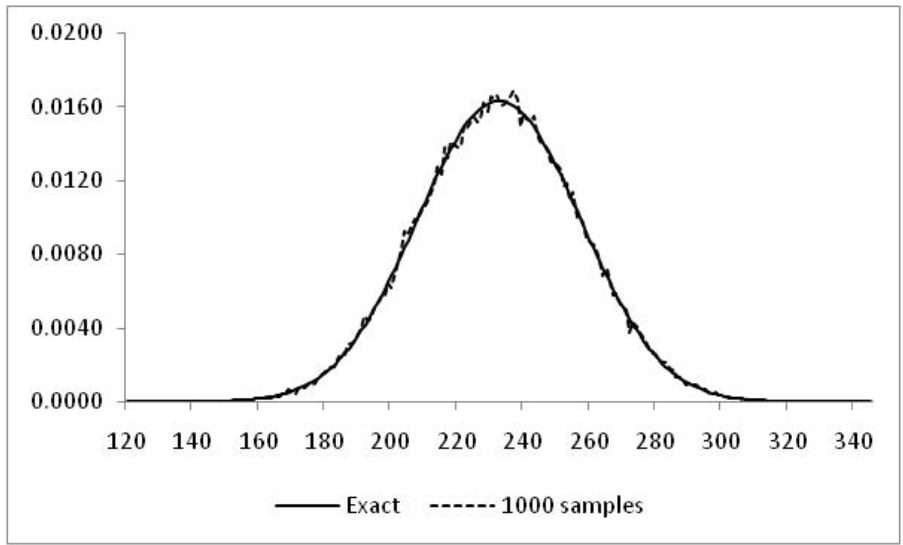

(b)

82 Iterations

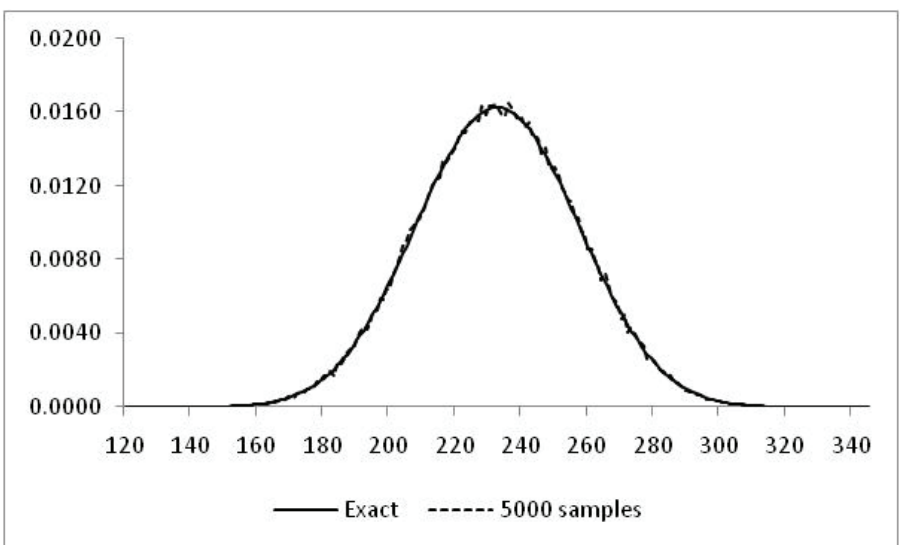

(d)

36 Iterations 
EMPIRICAL SAMPLING FROM PERMUTATION SPACE WITH UNIQUE PATTERNS

Table 2: Lower and Upper Critical Values for the Siegel-Tukey Test Statistic

\begin{tabular}{|c|c|c|c|c|c|c|c|c|}
\hline \multicolumn{2}{|c|}{ Sample Size } & \multirow{2}{*}{$\mathrm{ST}_{0.9000}$} & \multirow{2}{*}{$\mathrm{ST}_{0.9500}$} & \multirow{2}{*}{$\mathrm{ST}_{0.9750}$} & \multirow{2}{*}{$\mathrm{ST}_{0.9900}$} & \multirow{2}{*}{$\mathrm{ST}_{0.9950}$} & \multirow{2}{*}{$\mathrm{ST}_{0.9975}$} & \multirow{2}{*}{$\mathrm{ST}_{0.9990}$} \\
\hline $\mathrm{n}_{1}$ & $\mathrm{n}_{2}$ & & & & & & & \\
\hline 3 & 2 & $\begin{array}{c}6 \\
12\end{array}$ & & & & & & \\
\hline 3 & 3 & $\begin{array}{c}7 \\
14\end{array}$ & $\begin{array}{c}6 \\
15\end{array}$ & & & & & \\
\hline 4 & 2 & $\begin{array}{l}11 \\
17\end{array}$ & & & & & & \\
\hline 4 & 3 & $\begin{array}{l}12 \\
20\end{array}$ & $\begin{array}{l}11 \\
21\end{array}$ & & & & & \\
\hline 4 & 4 & $\begin{array}{l}13 \\
23\end{array}$ & $\begin{array}{l}12 \\
24\end{array}$ & $\begin{array}{l}11 \\
25\end{array}$ & & & & \\
\hline 5 & 2 & $\begin{array}{l}17 \\
23\end{array}$ & $\begin{array}{l}16 \\
24\end{array}$ & & & & & \\
\hline 5 & 3 & $\begin{array}{l}18 \\
27\end{array}$ & $\begin{array}{l}17 \\
28\end{array}$ & $\begin{array}{l}16 \\
29\end{array}$ & & & & \\
\hline 5 & 4 & $\begin{array}{l}20 \\
30\end{array}$ & $\begin{array}{l}18 \\
32 \\
\end{array}$ & $\begin{array}{l}17 \\
33 \\
\end{array}$ & $\begin{array}{l}16 \\
34 \\
\end{array}$ & & & \\
\hline 5 & 5 & $\begin{array}{l}21 \\
34\end{array}$ & $\begin{array}{l}20 \\
35\end{array}$ & $\begin{array}{l}18 \\
37\end{array}$ & $\begin{array}{l}17 \\
38\end{array}$ & $\begin{array}{l}16 \\
39\end{array}$ & $\begin{array}{l}16 \\
39\end{array}$ & \\
\hline 6 & 2 & $\begin{array}{l}23 \\
31\end{array}$ & $\begin{array}{l}22 \\
32\end{array}$ & & & & & \\
\hline 6 & 3 & $\begin{array}{l}25 \\
35 \\
\end{array}$ & $\begin{array}{r}24 \\
36 \\
\end{array}$ & $\begin{array}{l}23 \\
37 \\
\end{array}$ & & & & \\
\hline 6 & 4 & $\begin{array}{l}27 \\
39\end{array}$ & $\begin{array}{l}25 \\
41\end{array}$ & $\begin{array}{l}24 \\
42 \\
\end{array}$ & $\begin{array}{l}23 \\
43\end{array}$ & $\begin{array}{l}22 \\
44\end{array}$ & & \\
\hline 6 & 5 & $\begin{array}{l}29 \\
43\end{array}$ & $\begin{array}{l}27 \\
45\end{array}$ & $\begin{array}{l}25 \\
47\end{array}$ & $\begin{array}{l}24 \\
48\end{array}$ & $\begin{array}{l}23 \\
49\end{array}$ & $\begin{array}{l}22 \\
50\end{array}$ & \\
\hline 6 & 6 & $\begin{array}{l}31 \\
47 \\
\end{array}$ & $\begin{array}{l}29 \\
49 \\
\end{array}$ & $\begin{array}{l}27 \\
51 \\
\end{array}$ & $\begin{array}{l}25 \\
53 \\
\end{array}$ & $\begin{array}{l}24 \\
54 \\
\end{array}$ & $\begin{array}{r}23 \\
55 \\
\end{array}$ & \\
\hline 7 & 2 & $\begin{array}{l}30 \\
40 \\
\end{array}$ & $\begin{array}{l}29 \\
41 \\
\end{array}$ & & & & & \\
\hline 7 & 3 & $\begin{array}{l}33 \\
44 \\
\end{array}$ & $\begin{array}{l}31 \\
46\end{array}$ & $\begin{array}{l}30 \\
47\end{array}$ & $\begin{array}{l}29 \\
48\end{array}$ & & & \\
\hline 7 & 4 & $\begin{array}{l}35 \\
49\end{array}$ & $\begin{array}{l}33 \\
51\end{array}$ & $\begin{array}{l}32 \\
52\end{array}$ & $\begin{array}{l}30 \\
54\end{array}$ & $\begin{array}{l}29 \\
55\end{array}$ & & \\
\hline 7 & 5 & $\begin{array}{l}37 \\
54\end{array}$ & $\begin{array}{l}35 \\
56\end{array}$ & $\begin{array}{l}34 \\
57\end{array}$ & $\begin{array}{l}32 \\
59\end{array}$ & $\begin{array}{l}30 \\
61\end{array}$ & $\begin{array}{l}29 \\
62\end{array}$ & \\
\hline 7 & 6 & $\begin{array}{l}40 \\
58\end{array}$ & $\begin{array}{l}37 \\
61\end{array}$ & $\begin{array}{l}35 \\
63\end{array}$ & $\begin{array}{l}33 \\
65\end{array}$ & $\begin{array}{l}32 \\
66\end{array}$ & $\begin{array}{l}31 \\
67\end{array}$ & $\begin{array}{l}29 \\
69\end{array}$ \\
\hline 7 & 7 & $\begin{array}{l}42 \\
63 \\
\end{array}$ & $\begin{array}{l}40 \\
65 \\
\end{array}$ & $\begin{array}{l}37 \\
68 \\
\end{array}$ & $\begin{array}{l}35 \\
70\end{array}$ & $\begin{array}{l}33 \\
72 \\
\end{array}$ & $\begin{array}{l}32 \\
73\end{array}$ & $\begin{array}{l}30 \\
75 \\
\end{array}$ \\
\hline 8 & 2 & $\begin{array}{l}39 \\
49\end{array}$ & $\begin{array}{l}38 \\
50\end{array}$ & $\begin{array}{l}37 \\
51\end{array}$ & & & & \\
\hline 8 & 3 & $\begin{array}{l}42 \\
54 \\
\end{array}$ & $\begin{array}{l}40 \\
56\end{array}$ & $\begin{array}{l}39 \\
57\end{array}$ & $\begin{array}{l}37 \\
59\end{array}$ & & & \\
\hline 8 & 4 & $\begin{array}{l}44 \\
60\end{array}$ & $\begin{array}{l}42 \\
62\end{array}$ & $\begin{array}{l}41 \\
63\end{array}$ & $\begin{array}{l}39 \\
65\end{array}$ & $\begin{array}{l}38 \\
66\end{array}$ & $\begin{array}{l}37 \\
67\end{array}$ & \\
\hline 8 & 5 & $\begin{array}{l}47 \\
65\end{array}$ & $\begin{array}{l}45 \\
67\end{array}$ & $\begin{array}{l}43 \\
69\end{array}$ & $\begin{array}{l}41 \\
71\end{array}$ & $\begin{array}{l}39 \\
73\end{array}$ & $\begin{array}{l}38 \\
74\end{array}$ & $\begin{array}{l}37 \\
75\end{array}$ \\
\hline
\end{tabular}


JUSTICE I. ODIASE

Table 2 (continued): Exact Critical Values for Siegel-Tukey Test Statistic

\begin{tabular}{|c|c|c|c|c|c|c|c|c|}
\hline \multicolumn{2}{|c|}{ Sample Size } & \multirow{2}{*}{$\mathrm{ST}_{0.9000}$} & \multirow{2}{*}{$\mathrm{ST}_{0.9500}$} & \multirow{2}{*}{$\mathrm{ST}_{0.9750}$} & \multirow{2}{*}{$\mathrm{ST}_{0.9900}$} & \multirow{2}{*}{$\mathrm{ST}_{0.9950}$} & \multirow{2}{*}{$\mathrm{ST}_{0.9975}$} & \multirow{2}{*}{$\mathrm{ST}_{0.9990}$} \\
\hline & & & & & & & & \\
\hline 8 & 6 & $\begin{array}{l}50 \\
70\end{array}$ & $\begin{array}{l}47 \\
73\end{array}$ & $\begin{array}{l}45 \\
75\end{array}$ & $\begin{array}{l}43 \\
77\end{array}$ & $\begin{array}{l}41 \\
79\end{array}$ & $\begin{array}{l}40 \\
80\end{array}$ & $\begin{array}{l}38 \\
82\end{array}$ \\
\hline 8 & 7 & $\begin{array}{l}53 \\
75\end{array}$ & $\begin{array}{l}50 \\
78\end{array}$ & $\begin{array}{l}47 \\
81\end{array}$ & $\begin{array}{l}44 \\
84\end{array}$ & $\begin{array}{l}43 \\
85\end{array}$ & $\begin{array}{l}41 \\
87\end{array}$ & $\begin{array}{l}39 \\
89\end{array}$ \\
\hline 8 & 8 & $\begin{array}{l}56 \\
80\end{array}$ & $\begin{array}{l}52 \\
84\end{array}$ & $\begin{array}{l}50 \\
86\end{array}$ & $\begin{array}{l}46 \\
90\end{array}$ & $\begin{array}{l}44 \\
92\end{array}$ & $\begin{array}{l}43 \\
93\end{array}$ & $\begin{array}{l}41 \\
95\end{array}$ \\
\hline 9 & 2 & $\begin{array}{l}48 \\
60\end{array}$ & $\begin{array}{l}47 \\
61\end{array}$ & $\begin{array}{l}46 \\
62\end{array}$ & & & & \\
\hline 9 & 3 & $\begin{array}{l}51 \\
66\end{array}$ & $\begin{array}{l}49 \\
68\end{array}$ & $\begin{array}{l}48 \\
69\end{array}$ & $\begin{array}{l}47 \\
70\end{array}$ & $\begin{array}{l}46 \\
71\end{array}$ & & \\
\hline 9 & 4 & $\begin{array}{l}55 \\
71\end{array}$ & $\begin{array}{l}52 \\
74\end{array}$ & $\begin{array}{l}50 \\
76\end{array}$ & $\begin{array}{l}49 \\
77\end{array}$ & $\begin{array}{l}47 \\
79\end{array}$ & $\begin{array}{l}46 \\
80\end{array}$ & \\
\hline 9 & 5 & $\begin{array}{l}58 \\
77\end{array}$ & $\begin{array}{l}55 \\
80\end{array}$ & $\begin{array}{l}53 \\
82\end{array}$ & $\begin{array}{l}51 \\
84\end{array}$ & $\begin{array}{l}49 \\
86\end{array}$ & $\begin{array}{l}48 \\
87\end{array}$ & $\begin{array}{l}47 \\
88\end{array}$ \\
\hline 9 & 6 & $\begin{array}{l}61 \\
83\end{array}$ & $\begin{array}{l}58 \\
86\end{array}$ & $\begin{array}{l}56 \\
88\end{array}$ & $\begin{array}{l}53 \\
91\end{array}$ & $\begin{array}{l}51 \\
93\end{array}$ & $\begin{array}{l}50 \\
94\end{array}$ & $\begin{array}{l}48 \\
96\end{array}$ \\
\hline 9 & 7 & $\begin{array}{l}64 \\
89\end{array}$ & $\begin{array}{l}61 \\
92\end{array}$ & $\begin{array}{l}58 \\
95\end{array}$ & $\begin{array}{l}55 \\
98\end{array}$ & $\begin{array}{c}53 \\
100\end{array}$ & $\begin{array}{c}51 \\
102\end{array}$ & $\begin{array}{c}49 \\
104\end{array}$ \\
\hline 9 & 8 & $\begin{array}{l}68 \\
94\end{array}$ & $\begin{array}{l}64 \\
98\end{array}$ & $\begin{array}{c}61 \\
101\end{array}$ & $\begin{array}{c}57 \\
105\end{array}$ & $\begin{array}{c}55 \\
107\end{array}$ & $\begin{array}{c}53 \\
109\end{array}$ & $\begin{array}{c}51 \\
111\end{array}$ \\
\hline 9 & 9 & $\begin{array}{c}71 \\
100\end{array}$ & $\begin{array}{c}67 \\
104\end{array}$ & $\begin{array}{c}63 \\
108\end{array}$ & $\begin{array}{c}60 \\
111\end{array}$ & $\begin{array}{c}57 \\
114\end{array}$ & $\begin{array}{c}55 \\
116\end{array}$ & $\begin{array}{c}53 \\
118\end{array}$ \\
\hline 10 & 10 & $\begin{array}{c}88 \\
122\end{array}$ & $\begin{array}{c}83 \\
127\end{array}$ & $\begin{array}{c}79 \\
131\end{array}$ & $\begin{array}{c}75 \\
135\end{array}$ & $\begin{array}{c}72 \\
138\end{array}$ & $\begin{array}{c}69 \\
141\end{array}$ & $\begin{array}{c}66 \\
144\end{array}$ \\
\hline 11 & 11 & $\begin{array}{l}107 \\
146\end{array}$ & $\begin{array}{l}101 \\
152\end{array}$ & $\begin{array}{c}97 \\
156\end{array}$ & $\begin{array}{c}92 \\
161\end{array}$ & $\begin{array}{c}88 \\
165\end{array}$ & $\begin{array}{c}85 \\
168\end{array}$ & $\begin{array}{c}82 \\
171\end{array}$ \\
\hline 12 & 12 & $\begin{array}{l}128 \\
172\end{array}$ & $\begin{array}{l}121 \\
179\end{array}$ & $\begin{array}{l}116 \\
184\end{array}$ & $\begin{array}{l}110 \\
190\end{array}$ & $\begin{array}{l}106 \\
194\end{array}$ & $\begin{array}{l}103 \\
197\end{array}$ & $\begin{array}{c}99 \\
201\end{array}$ \\
\hline 13 & 13 & $\begin{array}{l}150 \\
201\end{array}$ & $\begin{array}{l}143 \\
208\end{array}$ & $\begin{array}{l}137 \\
214\end{array}$ & $\begin{array}{l}131 \\
220\end{array}$ & $\begin{array}{l}126 \\
225\end{array}$ & $\begin{array}{l}122 \\
229\end{array}$ & $\begin{array}{l}118 \\
233\end{array}$ \\
\hline 14 & 14 & $\begin{array}{l}175 \\
231\end{array}$ & $\begin{array}{l}167 \\
239\end{array}$ & $\begin{array}{l}161 \\
245\end{array}$ & $\begin{array}{l}153 \\
253\end{array}$ & $\begin{array}{l}148 \\
258\end{array}$ & $\begin{array}{l}144 \\
262\end{array}$ & $\begin{array}{l}138 \\
268\end{array}$ \\
\hline 15 & 15 & $\begin{array}{l}201 \\
264\end{array}$ & $\begin{array}{l}193 \\
272\end{array}$ & $\begin{array}{l}185 \\
280\end{array}$ & $\begin{array}{l}177 \\
288\end{array}$ & $\begin{array}{l}172 \\
293\end{array}$ & $\begin{array}{l}167 \\
298\end{array}$ & $\begin{array}{l}161 \\
304\end{array}$ \\
\hline 20 & 20 & $\begin{array}{l}362 \\
458\end{array}$ & $\begin{array}{l}349 \\
471\end{array}$ & $\begin{array}{l}338 \\
482\end{array}$ & $\begin{array}{l}325 \\
495\end{array}$ & $\begin{array}{l}316 \\
504\end{array}$ & $\begin{array}{l}308 \\
512\end{array}$ & $\begin{array}{l}298 \\
522\end{array}$ \\
\hline 30 & 30 & $\begin{array}{c}828 \\
1002\end{array}$ & $\begin{array}{c}804 \\
1027\end{array}$ & $\begin{array}{c}783 \\
1047\end{array}$ & $\begin{array}{c}759 \\
1071\end{array}$ & $\begin{array}{c}743 \\
1088\end{array}$ & $\begin{array}{c}728 \\
1102\end{array}$ & $\begin{array}{c}710 \\
1121\end{array}$ \\
\hline 40 & 40 & $\begin{array}{l}1487 \\
1754\end{array}$ & $\begin{array}{l}1449 \\
1791\end{array}$ & $\begin{array}{l}1417 \\
1824\end{array}$ & $\begin{array}{l}1380 \\
1861\end{array}$ & $\begin{array}{l}1354 \\
1886\end{array}$ & $\begin{array}{l}1331 \\
1910\end{array}$ & $\begin{array}{l}1303 \\
1937\end{array}$ \\
\hline 50 & 50 & $\begin{array}{l}2339 \\
2711\end{array}$ & $\begin{array}{l}2286 \\
2764\end{array}$ & $\begin{array}{l}2241 \\
2809\end{array}$ & $\begin{array}{l}2189 \\
2861\end{array}$ & $\begin{array}{l}2153 \\
2898\end{array}$ & $\begin{array}{l}2122 \\
2930\end{array}$ & $\begin{array}{l}2082 \\
2970\end{array}$ \\
\hline
\end{tabular}




\section{EMPIRICAL SAMPLING FROM PERMUTATION SPACE WITH UNIQUE PATTERNS}

\section{References}

Agresti, A. (1992). A survey of exact inference for contingency tables. Statistical Science, 7, 131-177.

Bayarri, M. J., \& Berger, J. O. (2004). The interplay of Bayesian and frequentist analysis. Statistical Science, 19, 58-80.

Darwin, C. (1878). The Effects of Cross and self-fertilization in the Vegetable Kingdom, $2^{\text {nd }} E d$. London: John Murray.

Devore, J. L. (1982). Probability and statistics for engineering and the sciences. California: Brooks/Cole Publishing Company.

Efron, B. (1982). The jackknife, the bootstrap, and other resampling plans. Philadelphia, PA: SIAM.

Ernst, M. D. (2004). Permutation methods: A basis for exact inference. Statistical Science, 19, 676-685.

Fahoome, G. (2002). Twenty nonparametric statistics and their large sample approximations. Journal of Modern Applied Statistical Methods, 1, 248-268.

Fisher, R. A. (1935). The design of experiments. Edinburgh: Oliver and Boyd.

Fisher, R. A. (1936). The coefficient of racial likeness and the future of Craniometry. Journal of the Royal Anthropological Institute, 66, 57-63.

Fisher, R. A. (1971). The design of experiments ( $\left.8^{\text {th }} E d.\right)$. New York: Hafner Publishing.

Friedman, M. (1937). The use of ranks to avoid the assumption of normality implicit in the analysis of variance. Journal of the American Statistical Association, 32(200), 675701.

Friedman, M. (1939). A correction: The use of ranks to avoid the assumption of normality implicit in the analysis of variance. Journal of the American Statistical Association, 34(205), 109.

Friedman, M. (1940). A comparison of alternative tests of significance for the problem of $\mathrm{m}$ rankings. The Annals of Mathematical Statistics, 11(1), 86-92.

Good, P. (2000). Permutation tests: a practical guide to resampling methods for testing hypotheses $\left(2^{\text {nd }} E d.\right)$. New York: Springer-Verlag.
Hall, P. and I. Weissman (1997). On the estimation of extreme tail probabilities. The Annals of Statistics, 25, 1311-1326.

Headrick, T. C. (2003). An algorithm for generating exact critical values for the Kruskal-Wallis one-way ANOVA. Journal of Modern Applied Statistical Methods, 2, 268-271.

Ludbrook, J., \& Dudley, H. (1998). Why permutation tests are superior to $\mathrm{t}$ and $\mathrm{F}$ tests in biomedical research. The American Statistician, 52, 127-132.

Odiase, J. I., \& Ogbonmwan, S. M. (2005a). An algorithm for generating unconditional exact permutation distribution for a two-sample experiment. Journal of Modern Applied Statistical Methods, 4, 319-332.

Odiase, J. I., \& Ogbonmwan, S. M. (2005b). Exact permutation critical values for the Kruskal-Wallis one-way ANOVA. Journal of Modern Applied Statistical Methods, 4(2), 609-620.

Odiase, J. I., \& Ogbonmwan, S. M. (2007a). Exact permutation of paired observations: The challenge of R. A. Fisher. Journal of Mathematics and Statistics, 3(3), 116-121.

Odiase, J. I., \& Ogbonmwan, S. M. (2007b). Exact permutation paradigm in multisample experiments. Advances and Applications in Statistics, 7(3), 417-434.

Opdyke, J. D. (2003). Fast permutation tests that maximize power under conventional Monte Carlo sampling for pairwise and multiple comparisons. Journal of Modern Applied Statistical Methods, 2, 27-49.

Scheffe, H. (1943) Statistical inference in the nonparametric case. The Annals of Mathematical Statistics, 14, 305-332.

Siegel, S., \& Castellan, N. J. (1989). Nonparametric statistics for the behavioural sciences ( $3^{\text {rd }} E d$.). New York: McGraw-Hill.

Spiegelhalter, D. J. (2004). Incorporating Bayesian ideas into health-care evaluation. Statistical Science, 19, 156-174.

Wald, A., \& Wolfowitz, J. (1944). Statistical tests based on permutation of the observations. The Annals of Mathematical Statistics, 15, 358-372. 
Appendix A: Unique Permutation Pattern Algorithm

This computer algorithm identifies and compiles the unique permutation patterns of the layout of observations or rank of observations in a two-sample experiment. It was implemented to produce a table of critical values for the Siegel-Tukey test statistic.

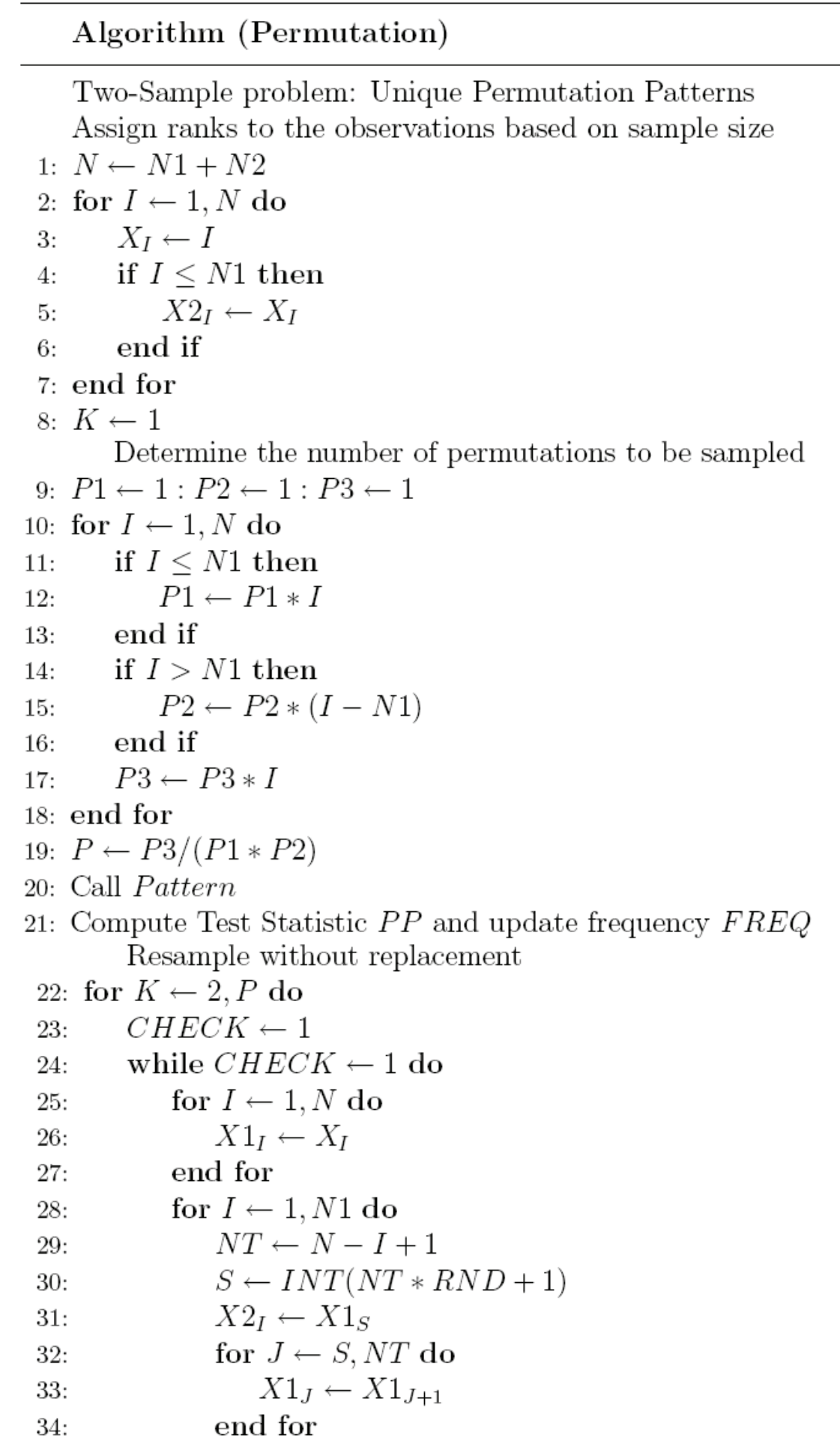


Appendix A (continued): Unique Permutation Pattern Algorithm

35: $\quad$ end for

36: Call Pattern

Ensure no repetition of permutations

37: $\quad C H E C K \leftarrow 0$

38: $\quad$ for $I 1 \leftarrow 1, K-1$ do

39: $\quad$ if $P A T_{K} \leftarrow P A T_{I 1}$ then

40: $\quad C H E C K \leftarrow 1$

41: $\quad$ end if

42: $\quad$ end for

43: $\quad$ if $C H E C K \leftarrow 1$ then

44: $\quad P A T_{K} \leftarrow " ”$

45: $\quad$ end if

46: $\quad$ end while

47: $\quad$ Compute Test Statistic $P P$ and update frequency $F R E Q$

48: end for

49: Sort $P P_{I}$ in ascending order for $I \leftarrow 1, C O U N T 1$

50: PRINT N1, N2

51: $P V \leftarrow 0$

52: for $I \leftarrow 1, C O U N T 1$ do

53: $\quad P D M \leftarrow F R E Q_{I} / P$

54: $\quad P V \leftarrow P V+P D M$

55: $\quad$ PRINT $P P_{I}, F R E Q_{I}, P D M, P V$

56: end for

\section{Algorithm (Pattern)}

1: Sort X2(I) for $I \leftarrow 1, N 1$ to have a unique pattern

2: for $J \leftarrow 1, N 1$ do

3: $\quad$ if $X 2_{J}<10$ then

4: $\quad P A T_{K} \leftarrow P A T_{K}+" 0 "+\operatorname{LTRIM}\left(\operatorname{RTRIM}\left(\operatorname{STR}\left(X 2_{J}\right)\right)\right)$

5: $\quad$ else $P A T_{K} \leftarrow P A T_{K}+\operatorname{LTRIM}\left(R T R I M\left(S T R\left(X 2_{J}\right)\right)\right)$

6: $\quad$ end if

7: end for 
Appendix A (continued): Unique Permutation Pattern Algorithm

\section{Algorithm (Permutation-Convergence)}

Unique Permutation Patterns: Iterate to convergence

Assign ranks to the observations based on sample size

1: $N \leftarrow N 1+N 2$

2: for $I \leftarrow 1, N$ do

3: $\quad X_{I} \leftarrow I$

4: $\quad$ if $I \leq N 1$ then

5: $\quad X 2_{I} \leftarrow X_{I}$

6: end if

7: end for

8: $B B \leftarrow 0$

9: $C K \leftarrow 1$

10: Ensure error tolerance is achieved

11: while $C K \leftarrow 1$ do

12: $\quad$ for $C 0 \leftarrow 1, C O U N T 1$ do

13: $\quad F R E Q_{C 0} \leftarrow 0$

14: end for

15: $\quad C O U N T 1 \leftarrow 0$

16: $\quad$ for $K \leftarrow 1, N N$ do

17: $\quad P A T_{K} \leftarrow " ”$

18: $\quad$ end for

19: $\quad B B \leftarrow B B+1$

Resample without replacement

20: $\quad$ for $K \leftarrow 1, N N$ do

21: $\quad C H E C K \leftarrow 1$

Ensure pattern is unique

22: while $C H E C K \leftarrow 1$ do

23:

for $I \leftarrow 1, N$ do

$X 1_{I} \leftarrow X_{I}$

end for

25:

26:

27:

for $I \leftarrow 1, N 1$ do

$N T \leftarrow N-I+1$

$S \leftarrow I N T(N T * R N D+1)$

$X 2_{I} \leftarrow X 1_{S}$

for $J \leftarrow S, N T$ do

$X 1_{J} \leftarrow X 1_{J+1}$

end for

end for

34:

Sort $X 2_{I}$ to have a unique pattern 
Appendix A (continued): Unique Permutation Pattern Algorithm

$35:$

36:

37:

38:

39:

40:

41:

42:

43:

44:

58:

59:

60:

61:

63:

64:

65:

66 :

67:

68:

69:

70 :

71 :

72 :

73:
Call Pattern

Ensure no repetition of permutations

$C H E C K \leftarrow 0$

for $I 1 \leftarrow 1, K-1$ do

if $P A T_{K} \leftarrow P A T_{I 1}$ then

$C H E C K \leftarrow 1$

end if

end for

if $C H E C K \leftarrow 1$ then

$P A T_{K} \leftarrow " "$

end if

end while

Compute Test Statistic $P P$ and update frequency FREQ

end for

Sort $P P_{I}$ in ascending order for $I \leftarrow 1, C O U N T 1$

Merge and Update pdf

if $B B>1$ then

$N P \leftarrow C O U N T 2+C O U N T 1$

for $I \leftarrow 1, N P$ do

if $I \leq C O U N T 2$ then

$U P D_{I} \leftarrow U P D 1_{I}$

$F R E Q_{I} \leftarrow F R E Q 1_{I}$

else

$U P D_{I} \leftarrow P P_{I-C O U N T 2}$

$F R E Q_{I} \leftarrow F R E Q 2_{I-C O U N T 2}$

end if

end for

for $J \leftarrow 1, C O U N T 2$ do

for $I \leftarrow C O U N T 2+1, N P$ do

if $U P D_{J} \leftarrow U P D_{I}$ then

$F R E Q_{J} \leftarrow F R E Q_{J}+F R E Q_{I}$

for $T \leftarrow I, N P-1$ do

$U P D_{T} \leftarrow U P D_{T+1}$

$F R E Q_{T} \leftarrow F R E Q_{T+1}$

end for

$N P \leftarrow N P-1$

end if

end for

end for

Sort the update $U P D$ in ascending order else 


\section{JUSTICE I. ODIASE}

Appendix A (continued): Unique Permutation Pattern Algorithm

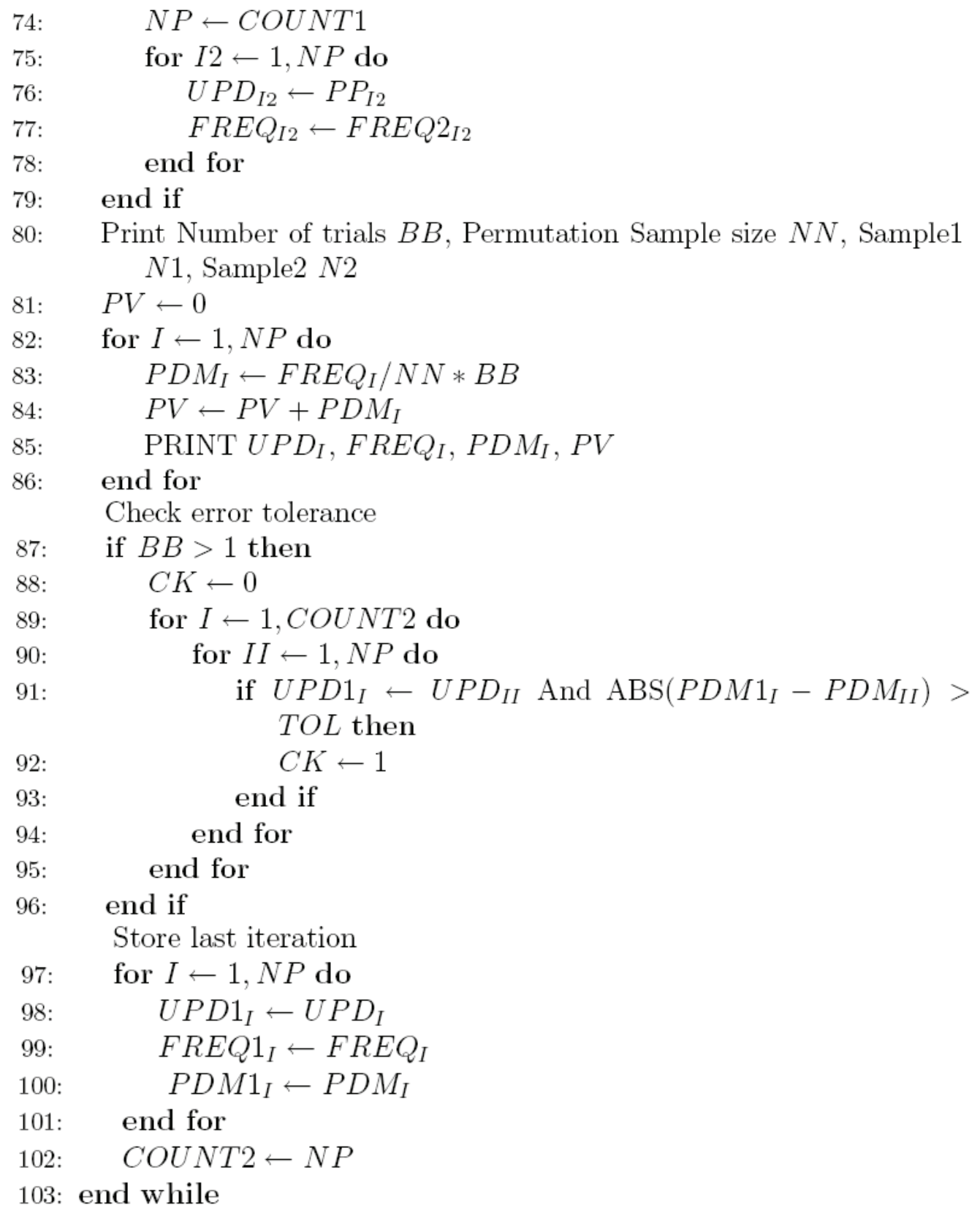

